\title{
Попова Е.А. \\ Возможности повышения эффективности управления удаленными сотрудниками малого и среднего бизнеса
}

Университет Синергия

doi: 10.18411/lj-04-2021-281

\section{Аннотация}

Основная цель работы - построить модель, которая позволяет удаленно работать на предприятиях, которые ищут возможности для повышения эффективности работы и снижения затрат. Определены преимущества, которые могут быть получены предприятиями, решившими использовать удаленную рабочую систему. Выявлены процессы, связанные с подготовкой, внедрением и улучшением системы удаленной работы.

Ключевые слова: дистанционные технологии, контроль, гибкая организация, режим удаленной работы

\section{Abstract}

The main goal of the work is to build a model that allows you to work remotely in enterprises that are looking for opportunities to improve operational efficiency and reduce costs. The benefits that can be obtained by enterprises that decide to use a remote working system are identified. The processes related to the preparation, implementation and improvement of the remote work system have been identified.

Keywords: remote technologies, control, flexible organization, remote work mode

Среди организаций, активно использующих новые решения в области удаленной работы, компании малого и среднего бизнеса считаются пионерами. Они только начинают внедрение модели удаленной работы, находя решения для улучшения взаимодействия в команде и выполнения задач. Появление и развитие удаленной работы способствовало необходимости пересмотра управления удаленными сотрудниками с учетом фактора расстояния (дисперсии). Новые дистанционные технологии в этой области позволяют эффективно делегировать, контролировать и сообщать о результатах работы, выполняемой вне офиса [4].

Связь удаленной работы с эффективной системой оценки и мониторинга работы связана с отбором людей с уникальной предрасположенностью к удаленному выполнению задач, а также с управлением сотрудниками в соответствии с их личными потребностями и ожиданиями. В некотором смысле, работе в удаленной системе необходимо «научиться» заново, и это наблюдение применимо как к сотрудникам, так и к предприятиям, в которых происходит глубокая трансформация структур: классические - иерархические и упорядоченные - больше не нужны. Совершенно гибкая организация становится новой действующей парадигмой, которая, среди прочего, он предназначен для сотрудников, которые могут предоставить ему конкурентное преимущество - независимо от их местонахождения [2].

Гибкость организационной структуры означает ее естественную изменчивость или возможность ее быстрого изменения или адаптации к потребностям предприятия и является результатом ее эффективности. Такая возможность создается за счет использования удаленной работы. Концепция удаленной работы, которая является основным элементом диссертации, может быть определена как предоставление работы вне организационной единицы работодателя с помощью средств, подпадающих под 
сферу информационных и коммуникационных технологий (электронная коммуникация).

С другой стороны, управление сотрудниками малого и среднего бизнеса в модели удаленной работы заключается в обеспечении эффективного взаимодействия между работодателем и удаленным работником, обмене знаниями и предотвращении профессионального выгорания удаленных сотрудников. Между этими двумя ключевыми концепциями существует заметный разрыв в определении конкретных организационных решений, что требует исследования методов и инструментов, используемых предприятиями малого и среднего бизнеса, использующими удаленную работу. Можно согласиться с тем, что существует необходимость в коренном изменении операционной стратегии предприятий, которая основана на использовании новых технологий как фактора совершенствования управления и повышения производительности труда персонала.

Выбор тематики работы во многом продиктован интересами автора и необходимостью углубления знаний и навыков, необходимых в профессиональной деятельности $[1,3]$. Это влечет за собой изменение пространственной организации предприятия и дает возможность использовать гибкие формы рабочего времени. В то же время задача состоит в том, чтобы найти сотрудников с особыми компетенциями на должности удаленных сотрудников, что требует внесения соответствующих изменений в процесс найма и отбора (отбор персонала). Режим удаленной работы требует хорошей организации, то есть синхронизации работы и деятельности всех членов команды. Современные инструменты, поддерживающие удаленную работу и в то же время создавая сеть взаимных межличностных связей, сокращают количество рабочего времени и эффективность работы по сравнению с офисными работниками.

С точки зрения работодателя, преимущество использования модели удаленной работы заключается в возможности контролировать эффект от реализации отдельных функций на постоянной основе. Более того, удаленная работа способствует снижению затрат, связанных с организацией рабочего места на предприятии, а также повышению эффективности работы. В последнем аспекте следует обратить внимание на тот факт, что в этой форме работы компания может привлечь сотрудников с уникальной высокой квалификацией, которые могут осуществлять работу из любой точки страны и даже мира.

Выявление и использование ключевых компетенций сотрудников может стать фактором, обеспечивающим конкурентное преимущество малому и среднему бизнесу. Основным элементом компетенций организации являются компетенции сотрудников, потому что именно люди, благодаря своим знаниям, навыкам, творчеству, продуктам и технологиям, влияют на производственные мощности и создают бренд компании.

На основе анализа конкретных примеров реализации удаленной работы можно построить модель - понимаемую как отображение определенных характерных решений в области удаленной работы - которая может стать ценным инструментом для компаний малого бизнеса, решающих внедрить удаленную работу и применить новую стратегия управления организацией труда. Удаленная работа (система управления удаленной работой) является новой, динамично развивающейся концепцией, которая имеет ряд последствий для функционирования современных организаций. Нами были выделены следующие особенности:

— есть новая тенденция, особенно заметная в ИТ-индустрии, которая напрямую связана с концепцией управления работой, основанная на мобильности сотрудников, возможности использования для выполнения работы мобильных устройств, таких как ноутбук, смартфон, планшет; 
— работа в удаленной системе приносит малому бизнесу ощутимые преимущества за счет повышения эффективности автономных сотрудников и сокращения расходов;

- удаленная работа открывает широкие возможности для развития высококлассных специалистов, которые без необходимости переезда могут обеспечить работой любого работодателя в мире;

— удаленная работа позволяет более эффективно нанимать сотрудников в сфере информационных технологий;

— удаленная работа ориентирована на результат - сотруднику учитывается выполненная работа, а не время, потраченное на работу, благодаря чему у него больше свободы, а он может более эффективно использовать свое время.

Такая модель должна учитывать различные потребности и ожидания отдельных заинтересованных сторон. Процесс его создания может быть длительным и сложным. Он приводит не только к изменениям в организации предприятия, но и в менталитете как потенциальных удаленных сотрудников, так и их руководства. Необходима культура управления с подходом, основанным на сотрудничестве и общении, которая поддерживает как удаленных сотрудников, так и менеджеров, отвечающих за всю виртуальную команду. Высокий уровень профессионализма удаленных работников означает, что организации с таким типом сотрудников в своих командах должны уделять особое внимание инновациям, позитивной конкуренции, обмену знаниями и информацией. Следовательно, они в некотором роде обязаны создавать культуру, основанную на компетенциях. Она становится ключевым элементом в достижении командных целей, в том числе в рамках удаленной работы, гарантирует эффективность и значимость предпринимаемых действий. Часто возникает проблема сосредоточения внимания на результатах работы, участии, компетенциях, называемых талантами. Эти переменные также должны стать сутью управления удаленными работниками для повышения эффективности деятельности.

Для повышения эффективности управления в режиме удаленной работы необходимо предоставить удаленным работникам инструменты, позволяющие выполнять поставленные задачи. Среди таких инструментов есть также решения, поддерживающие поток информации между удаленными работниками и сотрудниками в штаб-квартире организации. ИТ-система предоставляет удаленным работникам информацию о задачах, которые необходимо выполнить, и позволяет передавать выполненные работы. Если удаленные работники работают вместе над определенной задачей, система обеспечивает удаленную совместную работу. Изменение организации работы на удаленную работу требует предоставления удаленному работнику компьютера с программным обеспечением, необходимым для выполнения работы, и быстрого доступа к Интернету. В зависимости от специфики работы конкретного человека набор может быть расширен другими элементами, например веб-камерой, принтером. Когда удаленный работник использует в своей работе информационные ресурсы в корпоративной сети, необходимо сделать их доступными удаленно. В то же время в компании назначается сотрудник / сотрудники, отвечающие за техническую поддержку удаленных сотрудников, например, путем удаленного решения технических проблем.

Подводя итог, можно сделать вывод, что переход на удаленную работу может предоставить малому бизнесу ряд преимуществ. Однако, для повышения эффективности управления удаленной работы важно обеспечить удаленных сотрудников техническими средствами, сформировать культуру взаимоотношений, 
которое должно быть основано на доверии, потому что доступные инструменты лишь в определенной степени позволяют руководителям контролировать своих подчиненных сотрудников.

1. Кошелева Т.Н. Проблемы в процессе организации государственной поддержки предпринимательских структур на цифровой основе // Ученые записки Санкт-Петербургского имени В.Б. Бобкова филиала Российской таможенной академии. 2020. №1 (73). С.58-62.

2. Ло Шуай Новые особенности сферы занятости на международном рынке труда // Социология. 2019. №2. С.142-151.

3. Мартынова М.Э., Камшилов С.Г. Специфика управления персоналом в условиях пандемии коронавируса // Общество, экономика, управление. 2020. №4. С.57-60.

4. Сорвина Т.А., Кошелева Т.Н. Особенности развития малых и средних предпринимательских структур в процессе становления цифровой экономики в сложных экономических условиях // Петербургский экономический журнал. 2020. №2. С.98-104.

\section{Щербаков В.А. \\ Формирование рейтинга эффективности компаний железнодорожного транспорта России}

Сибирский государственный университет путей сообщения (Россия, Новосибирск)

doi: 10.18411/lj-04-2021-282

\section{Аннотация.}

В статье показана необходимость и важность формирования рейтинга эффективности компаний. Приведен показатель, используемой в мировой практике для рейтингования компаний по эффективности и изложен алгоритм его расчета применительно к особенностям российской экономики. Приведены результаты формирования рейтинга эффективности для четырех российских компаний, осуществляющих грузовые железнодорожные перевозки.

Ключевые слова: рейтинг эффективности компаний, коэффициент Тобина, стоимость бизнеса, инвестированный капитал, железнодорожный транспорт.

\section{Abstract}

The article shows the necessity and importance of forming a rating of companies' efficiency. The indicator used in world practice for rating companies in terms of efficiency is presented and an algorithm for its calculation in relation to the specifics of the Russian economy is presented. The results of the formation of an efficiency rating for four Russian companies engaged in freight rail transportation are presented.

Keywords: company performance rating, Tobin ratio, business value, invested capital, rail transport.

Рейтинги компаний составляются повсеместно и имеют целью проинформировать заинтересованных лиц в информации о показателях деятельности компаний. Например, компании рейтингуются по величине выручки, величине совокупных активов, показателях выполненных объемах работ в натуральном выражении и по многим другим показателям. применительно к компаниям железнодорожного транспорта широко известен рейтинг, ежегодно формируемый агентством INFOLINE. В таблице 1 приведена выписка из данного рейтинга. Приведенный рейтинг ориентирован, как представляется, на потребителей транспортных услуг, выбирающих поставщика транспортных услуг, и, возможно, региональные и отраслевые органы управления, принимающие решения о формировании государственных программ развития транспортной инфраструктуры. 